\title{
Editorial
}

\section{Does laparoscopic donor nephrectomy put pediatric recipients at risk?}

Laparoscopic donor nephrectomy (LDN) was first described in 1995 (1). The technique was quickly adopted by many transplant programs and by 2000, half of the living donor nephrectomies for adult recipients were being performed laparoscopically (2). Concerned there was more enthusiasm than science behind this trend, we conducted the first prospective randomized trial comparing LDN with open donor nephrectomy (ODN) and demonstrated conclusive benefits to the donor with respect to post-operative recovery (3). Outcomes for the LDN adult recipients were comparable as well, though this study was not powered to examine this endpoint. Over the years, multiple large series have been published. While some early series reported higher rates of delayed graft function (DGF) and ureteral complications, the majority of reports have suggested potential benefits to the donor and equivalent outcomes for the recipient compared with ODN. A review of the OPTN/UNOS database of adult kidney recipients transplanted between November 1999 and December 2000 suggested that LDN was associated with similar rates of DGF, acute rejection and one yr graft survival compared with ODN (4). This report also noted that LDN was associated with slower early graft function, though this conclusion is based on a slightly higher discharge creatinine in the LDN recipients who left the hospital slightly earlier than the ODN group. Subsequently, a systematic review of 44 published series, nearly all focusing on adult recipients, concluded the LDN and ODN were similar with respect to short-term donor and recipient outcomes in the adult population (5). From the recipients' perspective, at least, the issue seems resolved in adult transplantation.

While LDN was quickly embraced as the new standard for adult recipients, there have been concerns regarding the impact on outcomes for pediatric recipients. This largely centers on the decrease in renal blood flow observed with the pneumoperitoneum in $\operatorname{LDN}(6,7)$, and how this could adversely interact with the potential relative hypoperfusion of the adult size kidney in the pediatric recipient $(8,9)$. These concerns are especially relevant in the smallest pediatric recipients, where such physiologic events could lead to higher rates of DGF, graft thrombosis, and graft loss. Independent of graft loss, reduction in renal blood flow following reperfusion could generate non-specific damage that might increase the risk for subsequent immunologically and non-immunologically mediated injury and therefore compromise graft survival over the long term.

Adoption of the LDN approach for pediatric recipients has lagged behind the adult recipient population. Nonetheless, by 2003, 66\% of the donor procedures were LDN (2). Initial reports from several centers suggested that outcomes following LDN for pediatric recipients were equivalent to ODN (10-12). More reports have followed, providing additional evidence of recipient equivalent outcomes (13-17). While some suggest that initial graft function, as measured by serum creatinine, is somewhat delayed compared with the ODN group (11), none have demonstrated an impact on long-term outcomes. In these series, the rates of surgical complications, DGF, acute rejection, and graft survival all appear equivalent.

While single center studies are reassuring, these reports only reflect a small number of children, and are underpowered to evaluate many of the issues. A review of the OPTN/ UNOS database by Troppmann and colleagues evaluated outcomes for LDN and ODN in pediatric recipients transplanted between January 2000 and June 2002. During this time, 44\% of the donor nephrectomies for recipients five yr of age or less, and $50 \%$ of those for recipients age six-18 yr, were reported as LDN. In the 212 
youngest children (five yr of age and below), LDN was associated with a fivefold higher $(12.8 \%$ vs. $2.5 \%)$ risk of delayed graft function and a threefold higher $(18.6 \%$ vs. $5.9 \%)$ risk of acute rejection in the first six months. There was a slightly less impressive but still statistically significant higher rate of DGF $(5.9 \%$ vs. $2.8 \%)$ and acute rejection $(22.5 \%$ vs. $15.6 \%)$ associated with LDN in the older pediatric recipients as well. Graft survival at one and two yr, however, was equivalent in both age ranges. In the multivariate analysis performed, LDN was an independent risk factor for acute rejection. Based on these findings, there were calls for caution and consideration for a prospective randomized trial of LDN vs. ODN in small pediatric recipients (18).

How does one reconcile this analysis with the single center reports? While this registry analysis adjusted for many factors, there are other variables such donor relation and center effects including surgical management, perioperative care, and immunosuppression regimens which were not accounted for. Additionally, LDN was less common in pediatrics transplantation overall, and in the younger children in particular, potentially reflecting a center effect or practice pattern. Is there a reporting bias? Are the rates of DGF and ACR in the ODN group representative? Dissecting these issues is difficult with registry analysis.

In the current issue of this journal, Dave et al. report a series of 11 children who underwent LDN transplant, and compare them with the 11 preceding children who underwent ODN transplant (19). Understanding that the hypothesis underpinning much of the concern for the use of LDN for pediatric recipients centers on the impact of LDN on graft blood flow, they performed blinded intra-operative Doppler ultrasound assessment of the allograft following reperfusion. They found no difference in the mean intra-operative resistive index (RI) between the LDN and ODN group (0.66 vs. 0.59, respectively). Additionally none of the LDN kidneys had an abnormal RI, as defined as $\mathrm{RI}<0.5$ or $>0.8$, whereas three children in the ODN group had abnormal RIs. Of note, the three recipients less than five $\mathrm{yr}$ of age in the LDN group all had normal intra-operative RIs. While the authors are to be commended for their attempts to address the proximal mechanism of concern, i.e., renal blood flow, there are still questions. Perhaps the greatest issue is that one could posit that the changes in renal blood flow attributable to LDN would occur several hours following reperfusion rather than intra- operatively. Indeed, as pointed out by the authors, Raiteri et al. demonstrated that abnormal RIs at $24 \mathrm{~h}$ were associated with DGF and barring technical vascular issues, intra-operative RIs are often normal even in patients who go on to develop DGF (20). A Doppler evaluation at $24 \mathrm{~h}$ in the current report would be instructive. Regardless of this shortcoming, Dave et al. noted no difference in serum creatinine, DGF, acute rejection, and graft survival between the two groups, adding to the handful of other single center reports.

Is the collective experience sufficient to exclude the possibility that LDN does not disproportionately impact the risk for the smallest recipients? There are fewer reports addressing this issue but there is evidence equivalent results can be obtained. The series by Singer et al. included nine LDN and five ODN recipients aged five $\mathrm{yr}$ or less and reported similar outcomes (15). We have subsequently updated our experience, and in a sub-analysis focusing on $10 \mathrm{LDN}$ recipients less than $20 \mathrm{~kg}$, these small recipients had equivalent creatinine clearance at five days and one-yr post-transplant, similar rates of acute rejection, and equivalent graft survival at one and three yr compared with 11 matched ODN recipients (21). Will a randomized trial evaluating the impact of LDN in small pediatric recipients ever be conducted? It seems unlikely. To detect a twofold increase in the rate of DGF (assuming an expected incidence of $2-4 \%$ ) a randomized trial would need several hundred patients in each group. Over the last decade in the US, there have been approximately 100 living donor transplants performed annually in recipient less than six yr of age (22). More importantly, a registry analysis that does not account for a center effect (2) does not provide sufficient rationale for such a trial in the face of all the published literature. LDN is also clearly the current standard in the United States. In 2007, 91\% of all living donors had LDN (23). The rate of LDN has also increased for pediatric recipients, and the difference in rates between the smaller and larger children is diminishing. From 2004 to 2007, 73.7\% of living donors for recipients age five yr of age or less, and $76.2 \%$ in the six -17 yr age range, were LDN. LDN is a mature procedure that should be offered to donors. Indeed, it is possible that in a few more years, ODN may represent a higher risk procedure for both recipients and donors based on lack of experience with the procedure.

Does LDN place the pediatric recipient at risk? The answer is of course yes. All surgical procedures, indeed all medical interventions, place patients at risk. Transplantation is unique in that 
outcomes can be impacted by components of two operations. Is the risk of LDN greater than that associated with ODN? It should not be. Any type of donor nephrectomy performed poorly can compromise graft survival. It is clear that at many programs, equivalent outcomes can be obtained using LDN. LDN must be done by experienced surgeons and performed well. There are important surgical aspects of LDN which must be given proper consideration, including proper volume loading of the donor, degree and duration of pneomoperitoneum, and gentle dissection and manipulation to minimize vasospasm. One must pay careful and ongoing attention to recipient outcomes. If one loses sight of these principles, results will suffer. All these points are equally valid with ODN.

What will keep the debate going? Is right sided LDN or LDN for a kidney with two arteries contraindicated for pediatric recipients? Are outcomes better with hand-assisted LDN or totally laparoscopic LDN? Again the guiding principle for both donors and recipients is to do the best operation possible, but there is no reason in 2008 that LDN is not the preferred approach, regardless of who the recipient is.

\section{John C. Magee}

Division of Transplantation,

Department of Surgery,

University of Michigan,

Ann Arbor, MI,

USA

E-mail: mageej@umich.edu

\section{References}

1. Ratner le, Ciseck LJ, Moore RG, Cigarroa FG, Kaufman HS, Kavoussi LR. Laparoscopic live donor nephrectomy. Transplantation 1995: 60: 1047-1049.

2. Troppmann C, McBride MA, Baker TJ, Perez RV. Laparoscopic live donor nephrectomy: A risk factor for delayed function and rejection in pediatric kidney recipients? A UNOS analysis. Am J Transplant 2005: 5: 175-182.

3. Wolf JS JR, Merion RM, Leichtman AB, et al. Randomized controlled trial of hand-assisted laparoscopic versus open surgical live donor nephrectomy. Transplantation 2001: 72: 284 290.

4. Troppmann C, Ormond DB, Perez RV. Laparoscopic (vs. open) live donor nephrectomy: A UNOS database analysis of early graft function and survival. Am J Transplant 2003: 3: $1295-1301$.

5. Tooher RL, Rao MM, Scott DF, et al. A systematic review of laparoscopic live-donor nephrectomy. Transplantation 2004: 78: 404-414.
6. McDougall EM, Monk TG, Wolf JS JR, et al. The effect of prolonged pneumoperitoneum on renal function in an animal model. J Am Coll Surg 1996: 182: 317-328.

7. London ET, Ho HS, Neuhaus AM, Wolfe BM, Rudich SM, PEREZ RV. Effect of intravascular volume expansion on renal function during prolonged $\mathrm{CO} 2$ pneumoperitoneum. Ann Surg 2000: 231: 195-201.

8. Salvatierra O JR, Sarwal M. Renal perfusion in infant recipients of adult-sized kidneys is a critical risk factor. Transplantation 2000: 70: 412-413.

9. Salvatierra O JR, Singh T, Shifrin R, et al. Successful transplantation of adult-sized kidneys into infants requires maintenance of high aortic blood flow. Transplantation 1998: 66: 819-823.

10. Kayler LK, Merion RM, Maraschio MA, et al. Outcomes of pediatric living donor renal transplant after laparoscopic versus open donor nephrectomy. Transplant Proc 2002: 34: 3097-3098.

11. Troppmann C, Pierce JL, Wiesmann KM, et al. Early and late recipient graft function and donor outcome after laparoscopic vs open adult live donor nephrectomy for pediatric renal transplantation. Arch Surg 2002: 137: 908-915.

12. Hsu TH, Su LM, Trock BJ, Ratner Le, Colombani P, KAVoussi LR. Laparoscopic adult donor nephrectomy for pediatric renal transplantation. Urology 2003: 61: 320-322.

13. Abrahams hM, Meng MV, Freise CE, Stoller ML. Laparoscopic donor nephrectomy for pediatric recipients: Outcomes analysis. Urology 2004: 63: 163-166.

14. Kim DY, Stegall MD, Prieto M, et al. Hand-assisted laparoscopic donor nephrectomy for pediatric kidney allograft recipients. Pediatr Transplant 2004: 8: 460-463.

15. Singer JS, Ettenger RB, Gore JL, et al. Laparoscopic versus open renal procurement for pediatric recipients of living donor renal transplantation. Am J Transplant 2005: 5: 2514-2520.

16. Baqi N, Stock J, Lombardo SA, Geffner S, Roberti I. Impact of laparoscopic donor nephrectomy on allograft function in pediatric renal transplant recipients: A single-center report. Pediatr Transplant 2006: 10: 354-357.

17. Bergman S, Feifer A, Feldman L, et al. Laparoscopic live donor nephrectomy: The pediatric recipient in a dual-site program. Pediatr Transplant 2007: 11: 429-432.

18. Salvatierra O, Sarwal M. Vulnerability of small pediatric recipients to laparoscopic living donor kidneys. Am J Transplant 2005: 5: 201-202.

19. Dave S, Farhat W, Pace K, Navarro O, Hebert D, Khoury AE. Effect of donor pneumoperitoneum on early allograft perfusion following renal transplantation in pediatric patients: An intraoperative Doppler ultrasound study. Pediatr Transplant 2008: 12: 522-526.

20. Raiteri M, Ferraresso M, Pozzoli E, et al. Value of intraoperative resistive index in kidney transplant. Transplant Proc 2005: 37: 2472-2473.

21. Brooks ML, Englesbe MJ, Moyer AS, et al. Long term follow-up of laparoscopic versus open donor nephrectomy in pediatric kidney transplant recipients (abstract). Innsbruck, Austria: 3rd World Congress of the International Pediatric Transplant Association, August 2005.

22. Magee JC, Krishnan SM, Benfield Mr, Hsu DT, Shneider BL. Pediatric transplantation, 1997-2006. Am J Transplant 2008: 8: 935-945.

23. Magee JC, Krishnan SM. SRTR analysis, January 2008. 